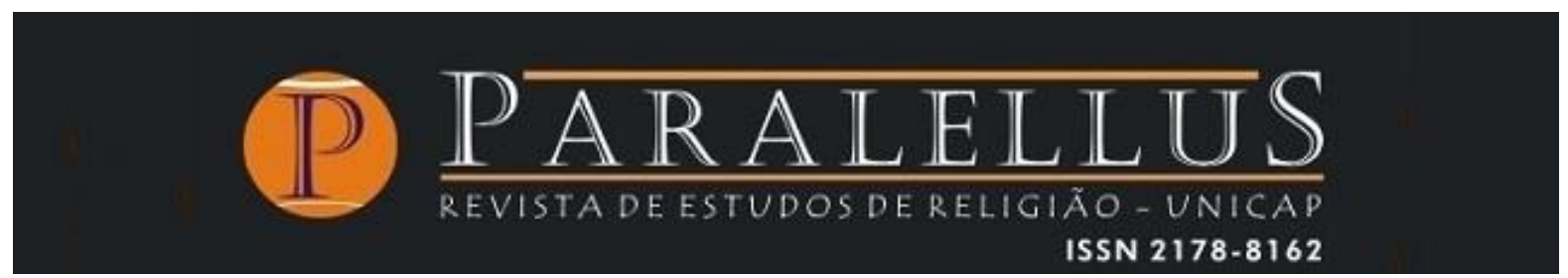

Volume 12 - Número 30

DOSSIÊ: A SABEDORIA NAS SAGRADAS ESCRITURAS

doi: 10.25247/paralellus.2021.v12n30.p369-382

\title{
APRENDENDO SOBRE EDUCAÇÃO COM A FILOSOFIA MADHYAMAKA
}

\section{LEARNING ABOUT EDUCATION WITH MADHYAMAKA PHILOSOPHY}

Prof $^{a}$ Dr $^{\underline{a}}$ Luciana Fernandes Marques*

\section{RESUMO}

O que é aprender? Qual é o propósito da educação? Como ensinar? Será que podemos encontrar algumas respostas ou indicações a essas perguntas em escritos de uma tradição mística como o Budismo? A ideia inicial do presente estudo foi buscar respostas a estas perguntas em um livro sobre a Escola Filosófica Madhyamaka sendo essa uma filosofia indiana do século II proveniente da antiga Universidade Nalanda. O objetivo principal do estudo foi o de analisar os usos e associações das palavras "ensinar" e "aprender" e estabelecer relações com os modos atuais pelos quais entendemos ensinar e aprender. Para a análise dos dados foi usada a Análise de Conteúdo de Bardin. As categorias apresentadas se referem às três perguntas iniciais formuladas. A partir das análises pode-se adentrar nesse contexto e observar a possibilidade de a academia estabelecer diálogos e discutir as sociedades atuais e suas práticas à luz de conhecimentos antigos.

Palavras-chaves: Educação; Ensino-aprendizagem; Budismo.

\section{ABSTRACT}

\footnotetext{
* Graduada em Psicologia (PUCRS, 1992), Mestre em Psicologia Social e da Personalidade (PUCRS, 1994), Doutora em Psicologia (PUCRS, 2001) e com Pós-Doutorado em Psicologia UFRGS (2008) e em Psicologia ISCTE-IUL, Lisboa (2013). Professora Associada II da Faculdade de Educação da UFRGS. Ministra disciplinas para os cursos de Pedagogia, Fisioterapia, Dança e Licenciaturas. Participa do Núcleo de Estudos da Religião (do Programa de Pós-Graduação em Antropologia Social da UFRGS).
} 
What is learning? What is the purpose of education? How to teach? Can we find any answers or indications to these questions in writings from a mystical tradition like Buddhism? The initial idea of the present study was to seek answers to these questions in a book about the Madhyamaka Philosophical School, which is a 2nd-century Indian philosophy originating from the old Nalanda University. The principal aim of the study was to analyze the uses and associations of the words "teach" and "learn" and relate to the current ways in which we understand teaching and learning. For data analysis, Bardin Content Analysis was used. The categories presented refer to the three initial questions. From the analysis, was possible to enter this context and observe the possibility of the academy to establish dialogues and discuss current societies' issues and their practices in the light of old knowledge.

Keywords: Education; Teaching-learning process; Buddhism.

\section{INTRODUÇÃO}

Este estudo foi realizado a partir de fontes bibliográficas e surgiu da curiosidade oriunda de estímulos diversos que parecem integrar em mim a psicóloga (que sou por formação), a educadora (que me tornei por convite da vida) e a budista (por conexão). Este estudo, em particular, parece trazer da psicologia a curiosidade sobre os processos internos pelo qual alguém aprende e o que o motiva a conhecer o mundo. Da educação veio o tema em si já que a educação é o próprio reino do aprender e do ensinar. Que outro tema poderia ser mais central do que esse na educação? Como budista me intriga que tradições antigas orientais tenham se disseminado tão amplamente no Brasil mas que tenhamos ficado num nível de compreensão superficial e que seu conhecimento antigo e profundo seja desconhecido ou, ainda, mal interpretado. Também me pergunto o quanto desse conhecimento oriental pode dialogar com temas que aqui nos interessam e que movem a nossa vida de alguma forma.

Participando e estudando junto a um grupo de pesquisa com base antropológica me chama atenção sua linguagem, estilos, referências e métodos. A magia de contar histórias dos antropólogos é encantadora. Eles viveram situações nos campos de investigação e as contam de forma inspirada e transparente sobre os percursos que seu pensamento/emoções foram seguindo ao longo da investigação junto ao contexto em estudo. Parecem um tanto audaciosos em não separar o objeto de estudo da consciência do pesquisador e, ao contrário, alguns fazem questão de explicitar a sua construção incluindo a própria subjetividade. Dessa forma, também apresentam 
culturas, formas de vida, visões de realidade - seja aprofundando o conhecimento de algo que já conhecemos ou indo para culturas e sistemas desconhecidos da maior parte dos seus leitores. Ao menos, essa é a minha interpretação.

Como pesquisadora tenho cultivado o hábito de desconfiar de tudo o que esteja presente no senso comum e até mesmo dos sensos comuns que se criam na própria academia e acabam tomando certa invisibilidade por serem tão encruados na percepção dos assim chamados objetos de pesquisa. Esse fenômeno que chamamos de ensinar e aprender e que não paramos pra examinar o que realmente significa e de que forma o construímos, pode ser um limitador da nossa prática docente. A partir da rigidez desse conceito e das práticas a que ele dá espaço, nossa própria experiência é moldada e certamente, também, limitada. Muito raramente extrapolamos esses limites, em especial na atividade de ensinar em que a responsabilidade é parte do legado da profissão docente.

Já o aprender é algo natural e constante em todo o ciclo vital do ser humano. Mas pouco pensamos que desaprender também seja algo natural, ou mesmo que haja espaço na vida para desaprender e reaprender (especialmente quando perdemos certos automatismos, como quando ficamos muito tempo sem andar de bicicleta, ou sem nadar, por exemplo). Quando aprendemos a nos locomover caminhando precisamos remover a noção de que engatinhar é a única e a melhor forma de se transportar. Nesse sentido, o aprender é desapegado, ou talvez haja certa busca pelo novo, pelo que vem a seguir e o que se deixa pra trás nem é percebido. $O$ aprender, em si, pode ser algo sem propósito e orgânico, regido só pelo sabor do descobrimento, de ver qual o resultado de certas ações, correr riscos e pagar para ver o que vem a seguir. O re-aprender também é parte da vida cotidiana. Um exemplo é quando nós, adultos, precisamos fazer certas "correções" com a ajuda de fonoaudiólogos, fisioterapeutas, nutricionistas ou mesmo psicólogos. Inicia-se um longo processo de desaprender certos hábitos, aprender outros e re-aprender (a falar, a se movimentar, a comer, a se comportar).

A observação dos resultados das nossas ações é algo aparentemente natural assim como as constatações que a seguem. Desde bebês, os humanos e outras espécies aprendem rapidamente a expressar suas necessidades e a manipular o ambiente para 
a sua satisfação. Ao explorar o ambiente, observa causas e efeitos, as possibilidades presentes numa certa situação, até que entenda como algo funciona e então se desinteresse em explorá-lo. Por exemplo, uma criança empilha e desempilha pequenos blocos de vários tamanhos repetidas vezes até dominar e entender o processo. Ela não é ensinada a observar, sua curiosidade é que a motiva. Ela observa pela curiosidade de ver o resultado e poder fazer diferente da próxima vez. E também observa pelo prazer em engajar-se em algo desafiador. Quando o processo é dominado, ela se desinteressa e parte para o aprendizado de outros processos. Isso é comumente observado quando se convive com crianças pequenas. Mas no senso comum o aprender já adquiriu outros significados e sobre ele foram impostas obrigatoriedades, ordens e arbitrariedades. Também foi separado um ambiente especial para o aprender (a escola), um tempo da rotina cotidiana e até um preço (exceto nas escolas públicas).

Mas aprender é um processo orgânico, natural, vital e ocorre em cada instante da vida humana (e provavelmente em outras formas de vida também) do nascimento à morte. Ao natural nos movemos pela vida em certas direções e não em outras. Também deixamos coisas para trás. Ganhamos e perdemos todo o tempo. Às vezes, inclusive ganhamos quando perdemos e perdemos quando ganhamos. Que relação esses movimentos tem com aprender e desaprender? Lembrando aqui a paradoxal frase de Lao Tsé, "Alguns ganham enquanto perdem, alguns perdem enquanto ganham". Aprendemos e desaprendemos todo o tempo. Como por exemplo ao levar à mão na tomada de luz, se você leva um choque, da próxima vez você se cuidará. Você agora aprendeu que tomadas são perigosas e desaprendeu a ter curiosidade por introduzir objetos em tomadas. Esses paradoxos são muito presentes em várias filosofias orientais. Neste estudo, em particular, a ideia é apresentar uma introdução às possibilidades de diálogo com a Escola Madhyamaka analisando um livro e visando escrutinar os sentidos e significados de ensinar e aprender nesse contexto.

Essa é uma filosofia indiana do século II proveniente da antiga Universidade Nalanda e que oferece uma visão de realidade bastante pontuada pela inefabilidade da verdade última que só poderia ser conhecida, em última instância, através de estados meditativos. A meditação é apontada por alguns autores como um complemento à aprendizagem e que junto com o estudo e o debate faria com que o conhecimento 
fosse assimilado de forma excelente (Gouveia, 2016). A meditação faz parte da educação monástica em várias vertentes do budismo juntamente com o estudo e o debate. A partir dessas observações surgiram algumas das questões deste estudo referentes ao que seja aprender, ensinar, desaprender e reaprender nessa filosofia. Mas antes, vale contextualizar já que a escola filosófica Madhyamaka é parte do budismo.

\section{BUDISMO E A ESCOLA MADHYAMAKA}

O budismo é tido como uma das religiões do mundo juntamente com o cristianismo, islamismo e judaismo (entre outras) (MASUZAWA, 2005). Uma das principais entradas históricas do Budismo no Brasil talvez tenha sido com a imigração de japoneses a partir de 1908 e sua tradição de Budismo Mahayana (GONÇALVES, 2005). Entretanto, ao longo de décadas, o budismo não foi crescendo como uma religião convencional no Brasil embora tenha se constatado uma disseminação e propagação do mesmo de variadas formas. Assim como Usarski (2004) descreve ao mencionar o quanto a mídia promove celebridades budistas e sua imagem positiva ao passo que estatisticamente os adeptos não chegam a $0.5 \%$ da população brasileira. Mas justamente em função do budismo não se prestar a ser uma religião convencional no sentido estrito, ao menos da forma como a maioria dos brasileiros vive a sua religiosidade, o budismo acaba ocupando o lugar de uma filosofia de vida, tendo mais simpatizantes do que propriamente adeptos ou convertidos religiosos. Muito provavelmente ele se preste tanto a ser vivido como uma religião, quanto a ser uma filosofia de vida com valores e visão de realidade não religiosa (em geral não dogmática e não necessariamente teísta).

A Escola Madhyamaka ou Escola do Caminho do Meio é parte do Budismo Mahayana, também chamado Grande Veículo. Foi fundada por Nagarjuna que viveu em torno do primeiro século no sul da Índia e é considerada uma escola filosófica de análise altamente crítica e dialética (GARFIELD, 1994). Um dos maiores e mais conhecidos textos de Nagarjuna é Mulamadhyamikakarika, "Versos fundamentais sobre o caminho do meio" (KALUPAHANA, 1986). A Escola Madhyamaka é escolhida como o contexto budista das investigações deste estudo porque ela apresenta uma visão que é comum a várias escolas budistas, ao Sutrayana, Mantrayana e a Grande 
Perfeição. Essa visão é a do caminho do meio que refuta qualquer visão extremista. Pessoalmente, penso que esta é uma das escolas que faz a síntese mais "científica" do budismo pelo rigor no exame minucioso, sem deixar de fora o mistério, o inefável, a vacuidade e até mesmo toda a poesia, a magia e a arte integrando tudo num sistema coerente e passível de análise.

Nas origens históricas da escola Madhyamaka, o debate girava em torno do niilismo em oposição ao eternalismo, os proponentes da escola Madhyamaka defendiam que nenhum desses extremos condiz com a realidade. Mais recentemente alguns filósofos proeminentes enfatizaram outros elementos relacionados à questões conceituais (JAMES, 2018) do quanto a imputação, a construção e a dependência de conceitos se relaciona com a noção de vacuidade que é para onde convergem a maioria dos ensinamentos budistas e também a escola Madhyamaka. Esse é apenas um dos debates filosóficos acerca da realidade presente em dita escola.

O objetivo geral deste estudo é analisar os usos e associações das palavras "ensinar" e "aprender" a partir da análise de um livro que representa a escola Madhyamaka. Este artigo faz parte de um estudo mais amplo que envolve o exame de outros materiais.

\section{Metodologia}

Para fins deste estudo a fonte a ser examinada é o livro "O caminho do meio: Fé baseada na razão" do Dalai Lama (2015). Esse livro foi baseado em ensinamentos que Dalai Lama proferiu em 2004 e que tem por base duas obras: três capítulos-chave de Mulamadhyamakakarika, "Estrofes fundamentais sobre o Caminho do Meio" de Nagarjuna (150 a 250 d.C), professor indiano do século II; e a obra "Três aspectos principais do Caminho", escrita originalmente em versos como uma carta de instrução da autoria de Jé Tsongkhapa (1357-1419). O livro analisado está em português e em formato eletrônico o que facilita a busca das palavras "aprend" e "ensin". Se as mesmas não forem escritas completas podem aparecer as palavras adjacentes como aprendizado, aprendeu, aprendizagem, aprendido, etc. valendo o mesmo para "ensin" (ensino, ensinar, ensinamento, ensinou, ensinado, etc.). 
Diferente de estudar um arquivo colonial (CUNHA, 2004) como seria numa etnografia documental, o livro aqui examinado possui outros objetivos, outros códigos e certamente outras chaves para serem acessados. Trata-se de um livro escrito por um mestre budista, mas que também é considerado um comentarista e um erudito da Filosofia Madhyamaka e que, ao apresentá-la ao longo do livro, inevitavelmente transita secundariamente pelo tema do aprender e do ensinar que é o que nos interessa para fins deste estudo. Vale lembrar que a Escola Filosófica Madhyamaka, ou Escola do Caminho do Meio não tem como objetivo explorar o tema do ensino ou da aprendizagem. Esses temas são transversais e necessários para que sua filosofia seja explicitada.

De certa forma, o autor se remete a determinada cultura (da Índia do século II) mas o foco aqui é observar como esses termos "aprender" e "ensinar" são usados, em que contexto e para se referir a que experiências. Para tanto será usado o método da Análise de Conteúdo de Bardin (1977) para responder à seguinte pergunta de pesquisa: Como as palavras "ensinar" e "aprender" (e palavras adjacentes) são usadas? Em que contextos? Conseguimos inferir significados do que seja ensinar e aprender conforme o modo como essas palavras são usadas?

Na fase da pré-analise houve a escolha do material a ser analisado e leitura flutuante do mesmo para ver a pertinência do uso dessa obra e não de outras para atingir os objetivos deste estudo.

O livro foi analisado no aplicativo Kindle (livro eletrônico) que permite a busca eletrônica de palavras. Então na fase de exploração propriamente dita do material: 1 . foi inserida a palavra no buscador do Kindle e cada frase em que a palavra buscada apareceu foi copiada e colada num arquivo de editor de texto; 2 . tal arquivo foi lido e houve uma primeira codificação, visando mais adiante aglutinar esses códigos em categorias mais amplas e explicativas. Abaixo dois exemplos dessa primeira codificação (que está em maiúsculas):

"E ainda por cima não aprendi quase nada de assuntos como matemática, história mundial ou geografia". APRENDER NO SENTIDO DE ABSORVER CONTEÚDO. 
positivas". APRENDIZAGEM COMO FORMA DE LIDAR COM A MENTE.

3. a primeira codificação foi reunida a partir da junção de frases codificadas da mesma forma. Essas codificações foram aglutinadas em sub-categorias que depois foram reunidas em categorias explicativas mais amplas sobre os sentidos dos usos da palavra através de um processo indutivo e inferencial e que respondam aos objetivos do estudo; 4. a seguir houve uma síntese final em categorias finais (mais amplas) e já discutindo o conteúdo reunido à luz dos autores da escola Madhyamaka e de teóricos atuais que contribuam a pensar visões diferenciadas de ensinar e aprender.

\section{CATEGORIAS: SÍNTESE DA ANÁLISE}

\subsection{O que podemos pensar sobre a aprendizagem?}

Ao longo do livro examinado, não surpreende que eventualmente tenha aparecido a referência às visões clássicas de ensino-aprendizagem: aprendizagem enquanto forma de absorver conteúdo, a visão da educação como transmissão de conhecimento e o professor como aquele que passa o conhecimento. Mas naturalmente isso não resume tudo o que o ensino é ou o que pode ser. Se o ensino ficasse circunscrito apenas a essa concepção, a escola seria o lugar de apenas assimilar informações dentro da tão criticada educação bancária (Freire, 1997). Mas naturalmente em se tratando de uma filosofia, a Escola do Caminho do Meio atrela a questão da educação ao educar-se e, para tanto, lidar com a própria mente ao referir que podemos aprender a controlar a própria mente se queremos ser felizes e como podemos lidar com a raiva, por exemplo.

Nesse ponto, a teoria do desenvolvimento de Jean Piaget e todos os estudos que vieram depois sobre a neurocognição e aprendizagem margeiam a importância de lidar com a mente, mas não chegam a colocá-la como centro do processo educacional, deixando-a apenas como anexa. Isto é, a partir de uma teoria psicológica de como a mente funciona são desenvolvidos métodos de ensino para que o objetivo do ensino se cumpra: a aprendizagem. Mas no processo de ensino-aprendizagem não há nenhum esforço de traduzir esse conhecimento da mente para o seu "possuidor", o/a aluno/a. Ele [Piaget] estava interessado em explicar como se forma e se desenvolve 
o pensamento infantil (Montoya, 2010). Não é o que se observa nesse livro em que parece haver uma preocupação em explicar como funciona a mente e como podemos lidar melhor com ela - num processo que é de aprendizagem.

\subsection{0 propósito da Educação}

No livro analisado, há apontamentos claros no sentido de exaltar a importância de conhecer e manipular a própria mente como quando o autor diz que você precisa aprender a controlar sua mente se você deseja ser feliz. Ele diz que a Filosofia Budista ensina que ações positivas (benéficas a si e aos outros) resultam em experiências prazeirosas e ações negativas trazem sofrimento. Tudo o que se aprende parece ter esse objetivo final: lidar com a própria mente de modo a ser feliz e fazer os outros felizes. E a Filosofia do Caminho do Meio pretende indicar a partir de quais pressupostos fazê-lo. Pode-se perceber que no sistema budista o processo de aprendizagem visa, em última instância, a felicidade ou a liberação do sofrimento para si e para todos os seres, o que poderia ser considerado um propósito soteriológico. Mas mesmo fora do budismo, lidar com a mente, ser feliz e desejar a felicidade para todos pode ser encarado como um propósito natural de todos os seres vivos. Mesmo um animal quer ser feliz e os humanos têm condições intelectuais de entender que somente com a felicidade dos outros a sua própria estará garantida. Difícil apontar qual a relação desse tópico com algo religioso. Parece mais um propósito educacional voltado para uma sociedade harmônica e equilibrada. Mas no suposto ensino escolar tradicional ocidental esse ponto não é realçado. O propósito é educar os jovens dentro da cultura que pertencem preparando-os para a vida, especialmente garantir habilidades e conhecimentos para ter um emprego e uma boa condição sócioeconômica, não atrelando isso, necessariamente, à felicidade pessoal ou à dos outros.

No Art. 2 da Lei de Diretrizes e Bases da Educação Nacional a educação é apresentada como dever da família e do Estado, "inspirada nos princípios de liberdade e nos ideais de solidariedade humana, tem por finalidade o pleno desenvolvimento do educando, seu preparo para o exercício da cidadania e sua qualificação para o trabalho" (Brasil, 1996). Para quem vive no Brasil, através dessa normativa, pode-se observar que o propósito da educação não inclui a felicidade nem para si e nem para os outros, nem o desenvolvimento de seres humanos íntegros e compassivos e etc. 
No livro, o autor esclarece que uma das justificativas para o estudo da Filosofia Madhyamaka é a transformação da própria mente visando beneficiar a si e aos outros. Não há dúvida que esse é um processo de aprendizagem com um propósito explícito. Aqui vale ressaltar que esse não apenas é um objetivo ou um propósito mas também a motivação inicial que faz com que alguém queira aprender. Dessa motivação se origina todo o resto. Via de regra a educação formal brasileira presente em todos os níveis desde o ensino fundamental até o ensino superior tem o propósito de tornar o sujeito apto ao trabalho e a viver numa sociedade de consumo que se mantém pelo esforço individual e capacidade de sustento. Entretanto há pessoas com excelentes níveis educacionais e de alto nível econômico que são infelizes ou ainda causam danos para si e para os outros. Nesse sentido podemos pensar que a educação pode ser usada de forma positiva ou negativa e o excesso de racionalismo via conteudismo talvez esteja minimizando a importância de educar a mente e as emoções que é o que garantiria um uso positivo e não individualista do conhecimento.

Do ponto de vista individual, do estudante, o propósito e a motivação para o estudo também devem estar presentes. O Dalai Lama diz que a busca por aprender deve ser movida pelo desejo de colocar o conhecimento em prática e que esse movimento deve ser a causa de uma maior liberdade (ou mesmo da liberação absoluta de todo sofrimento). Isto é, o conhecimento visa algo na vida daquele que aprende. $O$ contraste com o ensino escolar que vemos em nossa sociedade é imenso. A grande maioria vai para para escola por obrigação e aprender é tido como um dever sem grandes questionamentos e sem propósito.

\section{3 $O$ que é aprender?}

Numa passagem do livro, Dalai Lama diz “...a interpretação de Nagarjuna a respeito do ensinamento de Buda". Essa passagem parece muito rica pois se vermos o Buda como professor e Nagarjuna como aluno, vemos que há uma interpretação do que é ensinado e não mera assimilação e repetição. Aprender, nesse sentido, é como que reconstruir o conhecimento, por isso é tão importante nessa filosofia que o estudo esteja acompanhado de contemplação e debate (Gouveia, 2016). A importância da contemplação segundo Gouveia (2016) é que a partir de uma reflexão profunda a compreensão é ampliada de forma não apenas intelectual mas experiencial. É como 
se checássemos a fundo o que significa aquele conhecimento, que sentido ele tem nas nossas vidas e como ele aparece no nosso cotidiano. Nesse sentido encontramos também em Piaget na sua epistemologia interacionista o pressuposto de que o aluno só aprenderá alguma coisa se construir um novo conhecimento, se agir e problematizar a sua ação mediante uma reflexão profunda (Becker, 1993).

Já o debate tem a função de exercitar o conhecimento revelando seus pontos obscuros e "sem respostas" e até hoje é parte do processo de aprendizagem nas escolas de filosofia budista. Segundo o Dalai Lama quando se chega ao ponto de desenvolver uma profunda convicção de que tal coisa é assim, isso será um indicativo de que se atingiu um entendimento derivado da contemplação ou reflexão que é um conhecimento mais profundo do que a mera memorização intelectual.

Isso é antagônico ao que Becker (1993) descreve como sendo o processo de aprendizagem numa concepção behaviorista (que é muito do nosso dito ensino tradicional). Nessa tudo que o aluno precisa fazer é ficar em silêncio, prestar atenção no professor, ficar quieto e repetir tantas vezes quantas forem necessárias, seja escrevendo, lendo, copiando até assimilar o conhecimento que o professor passou. Igualmente na corrente empirista na educação os processos internos dos alunos e o modo como a sua mente funciona não são tópicos de interesse já que, via de regra, o estudante é considerado como uma página em branco, uma tábula rasa ou um bloco de argila a ser modelado pelo professor. Neves e Damiani (2006) dizem que nessa corrente "há uma preocupação excessiva em organizar o ensino, baseando-se na idéia de que "ensinando bem, o aluno aprende" (p. 3). A ideia é modelar o aluno de fora para dentro sendo ele um sujeito passivo. As escolas que adotam essa visão podem cometer uma violência oculta nos seus currículos e modos de ensinar. As necessidades emocionais dos alunos não são consideradas, a sua singularidade é perdida e a sua motivação esquecida.

\subsection{Como ensinar?}

Será que podemos pensar numa ação pedagógica que tenha por base alguns dos pressupostos implícitos à Filosofia Madhyamaka? Certamente! Há indicação de certa postura e qualidades do professor no livro analisado. Assim como para aprender, ensinar requer uma motivação elevada. Na filosofia budista a questão da motivação é 
o ponto inicial. "O professor deve se assegurar de que não ensina movido por um desejo de respeito, fama ou gratificação financeira; deve ser motivado essencialmente pelo desejo de bem-estar de todos os seres sencientes". Além de ter uma motivação benéfica, o professor deve considerar a diversidade dos seus alunos, suas faculdades mentais, tendências e interesses e ensinar de acordo com isso, ensinando diferente para alunos diferentes.

Num artigo provocativo sobre Educação Contemplativa (RANGEL, 2019), pode-se ver alguns pressupostos e realizações do mestre tibetano Chogyal Trungpa que fundou a Universidade Naropa no Estados Unidos. Ali é dito que haveria três formas de ensinar: 1. por meio de palavras, conceitos e ideias em que as palavras apenas indicam que experiências deve-se ter; 2 . Através da criação de um contexto particular em que não importa tanto o que o professor faz mas sim as situações que ele cria; e, 3. O professor compartilhar a sua mente com o aluno. Esta última pode possuir alguns significados mais místicos, mas no contexto educacional fora do budismo pode-se imaginar que essa seja a relação mais direta e comprometida que um professor pode ter com seu aluno. O compromisso de não ocultar absolutamente nada compartilhando tudo o que sabe (compartilhando sua mente). Ele sugeria que aqueles que ensinavam deveriam falar com o coração e não com o intelecto já que o aluno lembrará da presença do professor e do ambiente criado e não do que ele disse. Dessa forma o silêncio também seria uma forma de ensinar bem como a participação em atividades do cotidiano. Por isso Trungpa gostava de realizar com seus alunos seminários intensivos de 3 meses em que poderiam conviver e fazer coisas juntos como atividades domésticas e também festas, o que gerava um clima de relaxamento total.

\section{CONSIDERAÇÕES FINAIS}

Ao pesquisar brevemente sobre a tradição Madhyamaka no espaço conciso deste artigo, chamou a atenção o quanto a meditação pode ser uma forma de "desaprender" tudo o que nos constitui enquanto seres sociais e culturais para que possamos chegar a uma outra visão, a verdadeira, conforme proclamado por seus defensores. Certamente uma visão pouco disseminada em meio às vastas divulgações de mindfulness (isso é tema para outro artigo...). 
Outro ponto a salientar é o alerta de Dalai Lama no livro analisado de que o propósito maior da educação não deve ser esquecido. Esse propósito não se refere apenas a ampliar a capacidade de alguém de incrementar suas riquezas, posses ou poder já que sabemos que isso não nos leva a uma sociedade mais equilibrada.

Esses dois pontos destacados acima revelam o quanto os sistemas filosóficos e religiosos possuem um vasto cabedal de conhecimento que é pouco "traduzido" para a linguagem acadêmica ou do senso comum fora de tais tradições. Nessa brevíssima análise de um livro representativo da Filosofia do Caminho do Meio aparece o quanto a nossa sociedade e a educação moderna poderiam se beneficiar desses conhecimentos de uma forma não religiosa, não dogmática e não teísta.

No caso da Filosofia Madhyamaka, o raciocínio lógico é usado para explicitar as limitações mesmas da excessiva racionalidade. Mas no contexto budista isso se dava em relacionamentos professor-aluno (mestre-discípulo) em que ensinar e aprender ficam presentes e evidentes nas narrativas. Por isso a análise desse livro. Assim, com alguma curiosidade de adentrar nesses contextos a academia pode estabelecer diálogos e discutir as sociedades atuais e suas práticas à luz de conhecimentos antigos.

\section{REFERÊNCIAS}

BARDIN, L. Análise de conteúdo. Lisboa: Edições 70 Ltda, 1977.

BECKER, F. Modelos Pedagógicos e Modelos Epistemológicos. Porto Alegre:

Paixão de Aprender, n. 5, p. 18-23, 1993.

BRASIL. LDB - Lei de Diretrizes e Bases da Educação Nacional. Lei 9394/96 BRASIL.

CUNHA, Olívia Maria Gomes da. Tempo imperfeito: uma etnografia do arquivo. Mana, v. 10, n. 2, p. 287-322, 2004.

DALAI LAMA. O caminho do meio: Fé baseada na razão. São Paulo: Global Editora e Distribuidora Ltda, 2015.

FREIRE, Paulo. Educação "bancária" e educação libertadora. Introdução à psicologia escolar, v. 3, p. 61-78, 1997.

GARFIELD, Jay L. Dependent Arising and the Emptiness of Emptiness: Why Did Nāgārjuna Start with Causation? Philosophy East and West, v. 44, n. 2, p. 219-250, abril 1994. 
GONÇALVES, Ricardo Mário. As flores do dharma desabrocham sob o Cruzeiro do Sul: aspectos dos vários" budismos" no Brasil. Revista USP, n. 67, p. 198-207, 2005.

GOUVEIA, Ana Paula. Introdução à filosofia budista. Pia Sociedade de São PauloEditora Paulus, 2016.

JAMES, Simon P. Madhyamaka, Metaphysical Realism and the Possibility of an Ancestral World. Philosophy East and West, v. 68, n. 4, p. 1116-1133, 2018.

KALUPAHANA, David. Nagarjuna: The Philosophy of the Middle Way. Albany: State University of New York, 1986.

KHYENTSE RINPOCHE, D. J. Introduction to the middle way: Chandrakirti's Madhyamakavatara. Seattle: Khyentse Foundation, 2003.

MASUZAWA, Tomoko. The invention of world religions: Or, how European universalism was preserved in the language of pluralism. Chicago: University of Chicago Press, 2005.

MONTOYA, Adrian O. Dongo. Piaget: imagem mental e construção do conhecimento. Unesp, 2010.

RANGEL, Yolanda Padilla. Educación Contemplativa en la Universidad Naropa, $i$ una propuesta pedagógica revolucionaria?. Caleidoscopio-Revista Semestral de Ciencias Sociales y Humanidades, n. 40, p. 253-278, 2019.

USARSKI, Frank. O dharma verde-amarelo mal-sucedido: um esboço da acanhada situação do Budismo. Estudos Avançados, v. 18, n. 52, p. 303-320, 2004. 